\title{
Transatlantica
}

Revue d'études américaines. American Studies Journal

\section{André Bleikasten. Philip Roth. Les ruses de la fiction.} Paris : Belin, 1999. 128 p. http://www.editions-belin.com.

\section{Géraldine Chouard}

\section{(2) OpenEdition}

Journals

Édition électronique

URL : http://journals.openedition.org/transatlantica/722

DOI : $10.4000 /$ transatlantica.722

ISSN : $1765-2766$

Éditeur

AFEA

Référence électronique

Géraldine Chouard, «André Bleikasten. Philip Roth. Les ruses de la fiction. », Transatlantica [En ligne], 1 | 2003, mis en ligne le 05 avril 2006, consulté le 29 avril 2021. URL : http://journals.openedition.org/ transatlantica/722; DOI : https://doi.org/10.4000/transatlantica.722

Ce document a été généré automatiquement le 29 avril 2021

\section{(c) (i) $\odot$}

Transatlantica - Revue d'études américaines est mis à disposition selon les termes de la licence Creative Commons Attribution - Pas d'Utilisation Commerciale - Pas de Modification 4.0 International. 


\section{André Bleikasten. Philip Roth. Les ruses de la fiction.}

Paris : Belin, 1999. 128 p. http://www.editions-belin.com.

\section{Géraldine Chouard}

1 On connaissait la prose riche et nuancée de Bleikasten sur Faulkner, l'auteur auquel il a consacré (une large part de) sa vie universitaire: dans la critique américaine contemporaine, son Parcours compte sans doute parmi les plus beaux. On découvre maintenant, avec cet ouvrage sur Roth, une plume sensible aux effets d'une autre écriture : trempée à l'encre de la complicité (et non plus de la mélancolie), elle dessine les contours d'une œuvre tout à la fois joueuse et sérieuse, d'une verve inépuisable, dont elle s'attache à articuler les motifs et les enjeux. Après Faulkner-le-père, voilà venu, en quelque sorte, Roth-le-frère. Changement de cap, changement de ton : le texte se place sous le signe d'une entente fort stimulante.

2 S'il n'avait guère écrit jusqu'alors sur Roth que des comptes-rendus dans La Quinzaine Littéraire, il est clair, à lire ce volume critique (publié dans la collection «Voix américaines ", chez Belin), que Bleikasten fréquente Roth depuis toujours. Et qu'il n'est pas prêt à le lâcher. Depuis Portnoy et son complexe (1969) jusqu' à La Tâche humaine (2000), dont les extraits cités sont traduits de sa main, il décline les «biographèmes » d'un auteur qu'il connaît par cœur: "l'enfance à Newark, les années d'étudiant, le passage à l'armée, les premières aventures sexuelles, un premier mariage désastreux, la notoriété au prix d'un roman à scandale, la vindicte des bien-pensants, les voyages en Europe de l'Est, les dépressions, le pontage coronarien, les années partagées avec Claire Bloom ». Pour ajouter aussitôt que si le ressort essentiel de l'écriture de Roth est de nature autobiographique, le travail critique doit se situer dans « l'écart qui ne cesse de se creuser entre la vie de l'écrivain et ses fictions». Et Bleikasten de citer Zuckerman, dans La Contrevie : « contrairement à l'opinion générale, c'est la distance entre la vie de l'écrivain et son roman qui constitue l'aspect le plus fascinant de son imagination ». Dont acte.

3 Pour dissiper d'autres malentendus qui s'attachent parfois à (la personne de) Roth, le point est fait sur les divers combats menés par cet «écrivain incommode» qui n'a 
jamais cessé de résister. A peu près à tout. A l'étiquette d'écrivain «juif-américain », pour commencer : sans désavouer sa judéité, il ne saurait s'y identifier : « comme tout véritable écrivain, il se définit non pas par ses appartenances mais plutôt contre elles " (12) et au passage, Bleikasten prend soin de le distinguer de ses contemporains, Bellow et Malamud, auxquels il n'a pas manqué d'être associé. Pour Roth, l'écriture n'est autre qu'une éternelle bataille menée contre la bêtise, et son œuvre est un immense règlement de comptes «avec les femmes, les rabbins, les hommes politiques, les psychanalystes, les critiques litéraires. Avec les autres comme avec lui-même ».

4 Après avoir salué son entrée " en beauté » dans le monde des lettres américaines avec Goodbye, Columbus, en 1959, Bleikasten signale les quelques faiblesses de romans écrits sous l'influence de ses modèles, Flaubert et James : Laisser Courir (1962), indigeste, et Quand elle était gentille (1967), peu inspiré. C'est avec l'odyssée priapique de Portnoy et son complexe (1969) que Roth se lance dans la pratique d'une fiction libérée, fantasque et provocatrice : "Roth devient enfin Roth ». "En roue libre », le romancier publie alors des textes qui se définissent par leur langue débridée : Tricard Dixon et ses copains (1971) et Le Grand Roman américain (1973), Le Sein (1973) jouant sur les registres du loufoque et du grotesque, avec une exorbitante audace.

5 Si chez Roth, fiction et autobiographie se sont toujours fait "la courte échelle », les dispositifs narratifs successifs ont donné chaque fois un tour d'écrou supplémentaire à la question de la relation entre auteur, narrateur et personnage. L'exercice est devenu périlleux à partir de Ma vie d'homme (1974), où les effets de dédoublement se sont singulièrement compliqués. Procédant à l'inventaire des "vies d'artiste » de Roth, Bleikasten détaille avec une remarquable finesse les trajectoires de David Kepesh, le Professeur de désir (1977), de Nathan Zuckerman, «le plus connu des Doppelgänger de l'écrivain ", L'Ecrivain fantôme (1979) figurant dans les deux autres textes de la trilogie, Zuckerman délivré (1981) et La Leçon d'anatomie (1983) ainsi que dans son épilogue, L'Orgie de Prague (1985). En réalité, la « zuckermanie » de Roth ne s'arrête pas là, loin s'en faut : dans La Contrevie (1987), d'une " confusion pirandellienne ", Nathan reparaît aux côtés de Henry, son frère, et leurs destinées s'entrecroisent dans un éblouissant jeu de reflets spéculaires et de bifurcations excentriques, au détour desquels sont abordées les brûlantes questions du statut de l'Etat hébreu et de l'identité juive collective. Mais toujours dans un cadre romanesque, c'est-à-dire « dialogique ».

6 Après ces exercices subtils d'autobiographie oblique, Roth passe aux aveux avec Les faits (1988). Ou plutôt, il continue de faire semblant, par le biais de dispositifs paratextuels qui dénaturent son projet (tel le sous-titre de ce texte: "autobiographie d'un romancier »). Puis il renouvelle l'expérience virtuose de "la mise en abyme » avec l'inclassable Tromperie (1990) et se livre encore à un "portrait de l'artiste en agent double " avec Opération Shylock (1993), qualifié d'«éblouissant tour de force». Seule exception à la règle, Patrimoine (1991), une histoire vraie, sans ironie cette fois : « ni vulgaire règlement de comptes ni banal éloge funèbre ", d'un ton "admirablement juste ", c'est ici, selon Bleikasten, « du meilleur Roth ».

7 Aux «ruses de la fiction» telle que les pratique Roth, Bleikasten est parfaitement rompu. Mais loin d'être désabusé par ses feintes identitaires, il saisit à chaque fois, dans les tours de passe-passe de l'illusionniste, la confession intime dont chaque texte porte le secret.

8 Le dernier chapitre, "Histoire(s) d'Amérique », est consacré aux derniers romans de Roth, déployés sur la vaste toile du continent. De toute évidence, c'est au Théâtre de 
Sabbath (1995) que va la préférence de Bleikasten, sensible au souffle (et au soufre) du «monstre magnifique» qui en est le héros. Avec La Pastorale américaine (1997), Roth renoue avec le genre classique américain de la jérémiade et le critique regrette que « ce requiem pour l'Amérique perdue » n'échappe pas à une certaine forme d'allégorisation entre le Bien et le Mal. Un travers que partage aussi à ses yeux J'ai épousé un communiste (1998) même si la question de l'identité y est posée dans des termes dignes d'intérêt. Enfin, au-delà de la question du " politiquement correct » auquel le roman se rattache, La Tâche humaine (2000) met en scène, par le biais de la transgression de barrières raciales, le miracle d'une "autogénèse réussie ». Une prouesse emblématique à tous égards de l'entreprise de Roth, pour qui, à chaque fois, il s'est agi « de récrire la vie, de se refaire une identité (comme on se refait une santé) par la magie des mots ».

9 Le mérite enchanteur du texte de Bleikasten tient à la force évocatrice de son analyse qui fait toujours la différence entre les différents registres d'une écriture forte et variée dont il a subtilement mis en lumière les complexes protocoles de narration. Sensible à la vérité qui se cache sous les pistes brouillées, son parcours critique se fraie un chemin parmi les simulacres de la représentation et sait entendre la rumeur élégiaque qui pointe à l'horizon d'un imaginaire jubilatoire. On ne se refait pas.

INDEX

Thèmes : Recensions

\section{AUTEUR}

GÉRALDINE CHOUARD

Université Paris 9 - Dauphine 